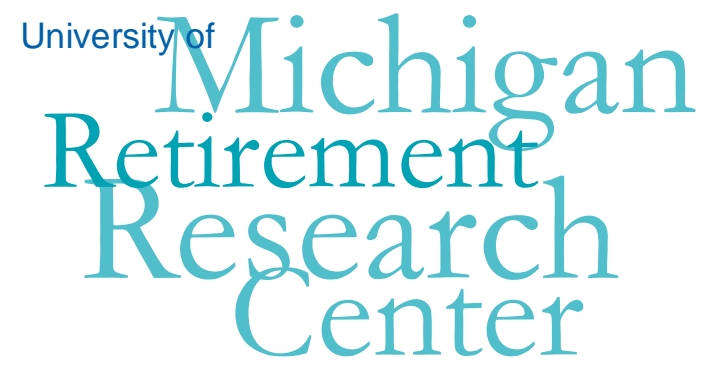

Working Paper

WP 2010-231

\title{
The Effects of the Economic Crisis on the Older Population
}

\author{
Michael D. Hurd and Susann Rohwedder
}

\begin{tabular}{|l|l|}
\hline $\mathrm{M}$ & $\mathrm{R}$ \\
\hline $\mathrm{R}$ & $\mathrm{C}$ \\
\hline
\end{tabular}

Project \#: UM10-06 



\title{
The Effects of the Economic Crisis on the Older Population
}

\author{
Michael D. Hurd \\ RAND, NETSPAR, NBER and MEA \\ Susann Rohwedder \\ RAND and NETSPAR
}

November 2010
Michigan Retirement Research Center
University of Michigan
P.O. Box 1248
Ann Arbor, MI 48104
http://www.mrrc.isr.umich.edu/
(734) 615-0422

\section{Acknowledgements}

This work was supported by a grant from the Social Security Administration through the Michigan Retirement Research Center (Grant \# 10-M-98362-5-01). The findings and conclusions expressed are solely those of the author and do not represent the views of the Social Security Administration, any agency of the Federal government, or the Michigan Retirement Research Center.

\section{Regents of the University of Michigan}

Julia Donovan Darrow, Ann Arbor; Laurence B. Deitch, Bingham Farms; Denise Ilitch, Bingham Farms; Olivia P. Maynard, Goodrich; Andrea Fischer Newman, Ann Arbor; Andrew C. Richner, Grosse Pointe Park; S. Martin Taylor, Gross Pointe Farms; Katherine E. White, Ann Arbor; Mary Sue Coleman, ex officio 


\title{
The Effects of the Economic Crisis on the Older Population
}

\begin{abstract}
We study the effects of the 2007-2009 recession on the population age 55 and older. Households in and near retirement have suffered sizeable losses in assets as a result of the economic crisis. There are a number of ways in which households might respond: reduce spending and with that increase saving, work longer, and/or bequeath less. Using longitudinal data from the Health and Retirement Study and its supplemental surveys, we find that all of these adjustments have been important.
\end{abstract}

\section{Authors’ Acknowledgements}

We are grateful for funding from the U.S. Social Security Administration (SSA) via the Michigan Retirement Research Center (UM10-06). The opinions and conclusions expressed are solely those of the author(s) and do not represent the opinions or policy of SSA or any agency of the Federal Government. 


\section{Introduction}

The Financial Crisis that unfolded so rapidly in the latter part of 2008 developed into a recession that stands out from other recessions of the post-World War II era in several important ways. First, and above all, the size of the swings in the economic environment were unequalled since the Great Depression. Second, the crisis has affected several markets simultaneously (housing, stock and labor market), consequently providing a number of channels through which individuals and their households might be affected.

The economic crisis and the subsequent increase in the unemployment rate have operated through several channels in ways that have affected people of different ages in differing ways. The post-retirement population is vulnerable to negative shocks in the stock and housing markets because of their asset positions, and somewhat less obviously because of linkages to their children. But they are relatively unaffected by unemployment. Furthermore, because of the importance of Social Security in the lower part of the income distribution, many of the less-well-off older households have been unaffected. The older pre-retirement population has also accumulated stocks, and because of the transition from DB to DC pensions, their sources of retirement income security are subject to risk. In addition, because of relatively high rates of labor force participation, they are vulnerable to unemployment: If they lose a job, they have little time to recover from those losses. In contrast to the retired population, those at the lower end of the income distribution are particularly vulnerable to unemployment. A broad generalization is that the effects of the economic crisis are widespread, affecting individuals from all parts of the income distribution. But it would seem that the retired population is actually likely to have suffered less than the pre-retired population.

The aim of this paper is to study the effects of the financial crisis on the population age 51 or older. We use longitudinal data from the Health and Retirement Study (HRS), a household data set that has observations from the time before the economic crisis began until it was well underway, with the latest available data point in 2009.

The housing market, after appreciating for some time, reached its maximum in May 2006. The stock market began to decline in October 2007. At first moderate, the 
pace of the decline increased rapidly, coinciding with the troubles in the financial sector that began in September 2008. By March 2009, it had reached its low point: The S\&P 500 had lost more than 50 percent from its peak 2007 level. While stocks have recovered somewhat since that time, the housing market has not. The HRS data-collected every two years since 1992 — span this period. Especially when combined with its supplemental data collections the HRS provides very rich information for the study of the effects of the financial crisis on older households: in 2001 the HRS began collecting longitudinal data on household spending, which is repeated every two years; in 2009, much of the HRS Internet study content was dedicated to eliciting information relevant to measuring the effects of the financial crisis. In this paper, we analyze changes in consumption associated with the crisis and examine housing, expectations, and retirement.

\section{Data}

The data for this study come from the Health and Retirement Study (HRS). We use data from the 2006 and 2008 core surveys, as well as from two supplemental studies, the Consumption and Activities Mail Survey (CAMS) and the HRS Internet Study. The HRS is a biennial panel. Its first wave was conducted in 1992, with the target population the cohorts born between 1931 and 1941 (Juster and Suzman, 1995). Additional cohorts were added in 1993 and 1998, so that in 2000, the HRS represented the section of the population from the cohorts of 1947 or earlier. In 2004, new cohorts were again added, making the HRS representative of the population age 51 or older.

\section{CAMS}

In September 2001, CAMS wave 1 was mailed to 5,000 households selected at random from households that had participated in HRS 2000. In couples households, it was sent to one of the two spouses at random. The fact that the CAMS sample was drawn directly from the HRS 2000 sample offered an important advantage: It allowed the CAMS data to be linked to the vast amount of information collected in prior waves of the HRS on the individuals and households who had been participating in the core survey. In 
2003, 2005, 2007, and 2009, CAMS waves 2-5 were sent to these same 5,000 households. ${ }^{1}$ To facilitate panel analysis, the structure of the questionnaire was almost the same in each of these waves. In this paper, we use CAMS data from all five waves.

CAMS asked respondents about their spending in each of 32 categories. This elicits almost the totality of spending according to the Consumer Expenditure Survey. The rates of item nonresponse were small. Some values could be imputed to zero with considerable confidence, due to the information in the linked HRS core data. For example, some homeowners (as recorded in the HRS core) did not report a value in CAMS for "rent”; we imputed rent of $\$ 0$ for these cases. ${ }^{2}$ The resulting spending levels are close to totals from the Consumer Expenditure Survey (CEX) for the age groups 5574. ${ }^{3}$ CAMS shows higher levels of spending than the CEX among those age 75 or over. There is no obvious reason that this difference should show in this age group, but not in the younger age group. However, we believe that the higher CAMS totals are more accurate than those in the CEX because they better match observed rates of wealth decumulation at older ages. ${ }^{4}$

\section{HRS Internet Survey}

The 2009 HRS Internet survey is the third wave in a series of Internet surveys of a subset of HRS respondents. Eligibility to participate in the 2009 wave was determined by whether, in the core HRS survey in 2008, a respondent reported regularly using the Internet. About 7,000 respondents qualified. ${ }^{5}$ The resulting sample tends to overrepresent those with higher education, but this bias is less strong for those age 65 or younger in the HRS. For this age group, Internet usage is more common throughout the distribution of both education and wealth. We have rich background information from the HRS core survey for those who did not participate in the HRS Internet Survey. This information can be used to re-weight any results from the Internet Survey. The field

\footnotetext{
${ }^{1}$ CAMS 2005 included, in addition, a sub-sample of the newly added cohort of the Early Baby-Boomers that was first recruited into the HRS sample as part of the HRS 2004 core survey.

${ }^{2}$ See Hurd and Rohwedder (2006).

${ }^{3}$ The CEX collects the most detailed and comprehensive information on total spending by households.

${ }^{4}$ When compared with after-tax income in the HRS, the lower levels of spending in CEX imply that single persons accumulate wealth, whereas in panel, they decumulate wealth (Hurd and Rohwedder, 2009).

${ }^{5}$ The unit response rate in the first two HRS Internet Surveys (conditional on being invited to participate) was $70 \%$.
} 
period was March 2009 through August 2009. For the purposes of this paper, we will refer to the data collection as having taken place in May 2009.

The HRS Internet survey has a module on the economic effects of the crisis on individual households, as well as modules on health and life satisfaction. In this paper, we use responses about the crisis's economic effects. We discuss the detailed items for analysis below, but broadly our approach is to find within-person changes in important outcomes that have resulted from the crisis.

\section{Effects of the Crisis on the Economic Circumstances of HRS households}

A broad gauge of the scale of the impact of the economic crisis is the simple response to a question about whether a respondent has been affected. About 28\% of respondents report that they have been affected a lot, about $46 \%$ say they have been affected a little, and just 26\% report not having been affected.

\section{Effects on Consumption}

According to the standard economic model, consumption is a better measure of economic well-being than income or wealth. We expect that households reduced consumption in response to the crisis. The HRS Internet survey asked respondents how their spending compared with a year earlier. In May 2008, prices in the housing market had begun to decline, but the stock market was still at a relatively high level; the large declines in stocks began later in the year. Unemployment was at 5.4\%, although it had been increasing. Accordingly, from the typical household's point of view, the economic crisis was still in the future.

Table 1 shows the percentages of respondents indicating in May 2009 that their spending had increased, decreased, or remained the same compared with a year earlier. In normal times, we would expect that for the younger age groups, spending would increase over a year. Indeed, that is what we observe in cross-section spending data. However, among respondents in their 50s, more than 30\% said their spending had decreased, whereas about 15\% said it had increased. At post-retirement ages, however, the pattern reverses, which is a first indicator that the older population was better protected from the effects of the crisis. 
The Internet survey contained follow-up questions to assess more directly the importance of various reasons for any changes in spending among respondents who reported having lowered their spending. Table 2 shows the percent who said that a stated reason for reducing spending was very important or somewhat important. Averaged over all ages, $85 \%$ of respondents indicated that being worried about the economic future was an important factor. Although the differences by age are not large, in the oldest age group that percentage was somewhat lower.

There is considerable disagreement in the literature about whether households change their spending in response to movements in asset prices such as stocks or housing. About half of respondents who had decreased spending attributed their actions to declines in asset prices (stocks and housing). With regard to the other reasons, there is a clear age gradient: The older population is less likely to have reduced spending because of the need to reduce debt, having a lower income, or rising unemployment levels.

In a similar manner, the Internet survey asked those respondents who said their spending had increased for the importance of various reasons. Broadly speaking, spending could increase due to greater economic resources (a positive reason) or due to need (possibly a negative reason). Table 3 shows the distribution of responses among those who said spending had increased. Almost all respondents cited increased spending needs. About half of the respondents were optimistic about their economic future-in sharp contrast with those who had reduced spending (Table 2). It is notable, however, that among those age 55-64, fewer had increased spending because of optimism. Because just $15 \%$ of this group had increased their spending (Table 1), the fraction of the total age 55-64 population that spent more because of optimism is only about 6\%.

About 1/3 of the 55-64 year olds cited better employment as a reason for increasing spending, compared with a negligible percentage in the oldest age group, those age 75 or older, who are mostly already retired. About $30 \%$ of those $55-64$ attributed more spending to higher mortgage payments. This is in line with an increase in mortgage debt (which we will examine directly below), and possibly with balloon mortgages that were a frequent financing instrument during the housing-market bubble.

All of these changes in consumption observed in the Internet survey are selfassessed. While a respondent may have good qualitative knowledge of the changes he or 
she had made, he or she is considerably less likely to have a good quantitative assessment. Accordingly, to quantify the magnitude of spending declines, we use CAMS. Our method is to compare two-year panel transitions in spending in "normal" times with two-year panel transitions during the economic crisis. We define normal times to be 2001-2007 and the time of the economic crisis to be 2007-2009. We average three panel transitions in spending (2001-2003, 2003-2005, and 2005-2007) so as to smooth out noise in the data and average out other macro shocks. We disaggregate by age band because the older population may have been better protected, as suggested by the self-assessed differences in changes in spending shown in Table 1.

Table 4 shows the changes in mean and median spending both in total and in nondurables, adjusted for price change. ${ }^{6}$ Among those age 50-64, mean total spending declined by about 2.1\% every two years, averaged over the period 2001-2007. This reduction is likely due to a number of reasons, such as changes in household composition or parental support for children's education. ${ }^{7}$ The decline in mean nondurable spending among this age group was about $1.0 \%$ per two-year period. Among those age 65 or older, the reductions were much greater: $6.3 \%$ in mean total spending and $4.9 \%$ in mean nondurable spending. These reductions are likely life-cycle effects. During the economic crisis, consumption fell at a much greater rate-almost $10 \%$ in the younger age group and 9\% in the older. The levels and changes in the medians are smaller, but the patterns are the same.

We summarize and compare the two age groups in Table 5. Among those age 5064, mean spending declined between 2007 and 2009 by 7.6 percentage points more than between 2001 and 2007. Among those 65 or older, spending declined by 3.4 percentage points more during the later period than in the earlier. Our interpretation is that, indeed, spending declined in response to the economic crisis, and that the comparisons of actual measured spending are consistent with the self-assessments in Table 1. Furthermore, consistent with our expectations that the older population was better protected against the

\footnotetext{
${ }^{6}$ These are derived from the ratios of mean and median spending. The mean of household-level spending change is not a good indicator of population spending change because observation error causes bias in the ratio.

${ }^{7}$ On average the two-year changes in household size among the 50-64 year old households show a decline of $6 \%$ for the 2001-2007 period.
} 
economic crisis and the self-reports of Table 1, spending by the older population declined less during the crisis than spending by the younger population.

\section{Effects on Housing}

Whether homeowners were affected by the large drops in home values, and how seriously they were affected, depends on where they live and when they bought their home. According to the Case-Shiller 20-city average, prices peaked in May 2006 at about 50\% above the level at which they had been at the beginning of 2003. But this average conceals substantial intercity variation. In Denver there was a moderate increase in housing prices, followed by a small decline. In Los Angeles and Phoenix, prices peaked at more than $100 \%$ above their 2003 value and have since declined by more than $50 \%$. In this sense, a family living in Denver would be relatively unaffected by price changes. But in contrast, a family living in Los Angeles or Phoenix might be affected, depending on the purchase date, method of financing, and the family's overall economic situation. For example, a family that bought a house in 2003 and took on a mortgage that was reasonable in relation to family income could have sound finances today, even though the value of the home has now dropped below its 2006 peak. However, if a family bought at the top of the market with a small percentage down-payment and a balloon loan, that family would now find itself with substantial negative home equity and increased mortgage costs that it might not be able to afford.

The HRS asks respondents about the value of their houses, both in the core survey and the Internet study. These data have the advantages of being reports on the same house over time and being nationally representative. Other commonly used data sources are based on recent actual property sales (possibly including refinanced properties) or in the Case-Shiller index, confined to 20 large cities.

Over several waves of the HRS, the rate of homeownership (assessed in panel) has been constant at almost 90\%. Table 6 shows mean and median house values, and mean and median mortgage values as reported by HRS respondents in 2006, 2008, and 2009. The mean house value declined modestly between 2006 and 2008 at about 4\% per year, and the median changed very little. ${ }^{8}$ Between 2008 and the HRS Internet survey,

\footnotetext{
${ }^{8}$ These price changes are not directly comparable with the Case-Shiller which is confined to 20 large cities.
} 
on average about nine months later, the decline was about $9 \%$. The decline in the median was about $11 \%$. These are, of course, very substantial reductions in the most important asset of most households. The mean value of mortgages was almost constant between 2006 and 2008, and the median declined by \$5 thousand. However, in just the short period between the 2008 HRS core interview and the HRS Internet interview, the mean value of mortgages increased by about $\$ 13$ thousand and the median by $\$ 21$ thousand. These increases suggest equity extraction, which may have made the household more vulnerable to other economic shocks such as unemployment. When combined with the reduction in house prices, the debt to value ratio had a large increase between 2008 and the Internet survey.

Table 6 is calculated in panel over all households that reported owning a home in all three surveys. But it includes some who did not fully report actual values for house price and for the mortgage. Most of the non-reporters reported a bracket. We exclude in Table 7 anyone with an imputed value because we want to report the fraction of households with negative housing equity: The imputation of a value even within a bracket could falsely classify some as having more mortgage than house value. A comparison of Table 7 with Table 6 shows that excluding respondents who reported incompletely does not materially affect the conclusions we make about the trends in home value and mortgage. The table shows that in 2006 and 2008, about 1\% of homeowners owed more than their house was worth. ${ }^{9}$ Among homeowners with a mortgage,1.4 - 1.8\% had negative equity. But by 2009, 4\% of all homeowners had negative equity and $6.67 \%$ of those with a mortgage had negative equity.

\section{House price expectations}

As reported in Table 2, an important reason for a reduction in spending was worries about the economic future. We assess one component of expectations about the economic future, house price expectations. Respondents are asked about expectations that their own home will appreciate in price in the form of a subjective probability as follows:

\footnotetext{
${ }^{9}$ These percentages of homeowners with negative equity are more representative of the population than those obtained from sources such as lenders or property records which are either incomplete or outdated.
} 
On a scale from 0 percent to 100 percent where 0 means that you think there is no chance and 100 means that you think the event is absolutely sure to happen, what do you think are the chances that by next year at this time your home will be worth more than it is today?

In follow-up questions, respondents were asked about additional price targets, such as an increase in value of 10 or $20 \%$ or a decrease in value of 10 or $20 \%$. Respondents were also asked the same question with a time horizon of five years.

Table 8 shows the average of those subjective probabilities. The average subjective probability that respondents' houses would be worth more in a year than they are today is just $32.3 \%$. This indicates that individuals are very pessimistic about the housing market, and these expectations are very much different from historical frequencies of house price gains. In 88\% of one-year intervals between 1991 and 2009, housing prices increased. ${ }^{10}$ Individuals are somewhat more optimistic over the five-year horizon: There the average subjective probability is about $54 \%$. But the discrepancy with the historical record is even greater, as in every five-year interval between 1991 and 2009 housing prices increased. ${ }^{11}$ Most likely, such pessimistic expectations are a partial explanation for the decline in spending reported in Tables 1 and 4.

\section{Stock market expectations}

Using the same format as for house price expectations, respondents are asked about the chances the stock market will be higher in a year. This question was asked in both HRS 2008 and in the HRS Internet survey, so we can make a direct panel comparison. Figure 1 shows the cumulative distribution of the reported subjective probabilities of any gain. The distribution for 2009 is shifted to the left of the distribution for 2008, showing a reduction in the average expectation of any gain. Indeed the average subjective probability declined from 52 percent probability in 2008 to 41 percent probability in the HRS Internet survey. The decline was particularly striking at the lower part of the distribution. At the 25th percentile, the subjective probability was 40 percent

\footnotetext{
${ }^{10}$ Calculated as the percentage of 12-month intervals over which the housing price index increased between January 1, 1991 to November 1, 2009.

${ }^{11}$ Calculated as the percentage of five-year intervals over which the housing price index increased between January 1, 1991 to November 1, 2009.
} 
in 2008. But it was just 20 percent in 2009. As with housing prices, such pessimistic expectations may explain some of the spending decline.

\section{Subjective Bequest Probabilities}

Using the same format as for the subjective probabilities of housing price gain and stock market price gain, HRS asked respondents about the probability they will leave a bequest greater than $\$ 10,000$. If this reported probability is positive, the question is repeated with a target of $\$ 100,000$ and then with a target of $\$ 500,000$. In cross-section, these subjective bequest probabilities vary positively with wealth, which increases our confidence that they are predictive of actual bequests. We expect some of the losses of assets between 2008 and 2009 will result in lower bequests as well as lower consumption.

Table 9 shows the implied distribution of probability mass in the population in each of the wealth intervals. Averaging over all responses, the probability of a bequest less than $\$ 10,000$ was 16.2 percent and the probability of a bequest between $\$ 10,000$ and $\$ 100,000$ was 19.8 percent. It is clear that between 2008 and 2009, the probability mass shifted toward the lower wealth bands, reflecting the loss of wealth.

We calculate expected bequests by multiplying the expected bequest within a wealth band by the probability of a bequest in that interval and then summing over all intervals. The expected bequest within an interval is calculated from the observed distribution of wealth in that interval in the 2008 HRS. The average wealth in the interval 0 to $\$ 10,000$ was $\$ 1,808$, and the expected contribution to bequests from that interval was $\$ 292$. Summing over all intervals, we find that expected bequests declined from $\$ 536$ thousand in 2008 to $\$ 436$ thousand in the HRS Internet survey. Of course this reduction is entirely dominated by the top interval, which is a result of the highly skewed distribution of wealth.

\section{Effects on Retirement}

The interval between the HRS 2008 interview and the 2009 Internet interview was too short to observe many actual retirements. However, over many waves, HRS has asked workers about retirement expectations (in the form of the subjective probability of working past age 62 and age 65). We call these subjective probabilities P62 and P65. 
They are predictive of actual retirement (Hurd, Reti and Rohwedder, 2009) and they have an advantage over data on actual retirement because changes in the subjective probability control for individual fixed effects, such as unmeasured permanent taste differences. Such fixed effects are difficult to control for when using data on actual retirement.

We expect that the financial crisis would have had two opposing effects on retirement. The declines in stock and possibly housing values should have delayed retirement because of the unexpected loss of wealth. Yet the worsening of the labor market and increased risk of unemployment should have led to earlier expected retirement because the older population often has more difficulty finding a job after a period of not working. The net effect is an empirical matter.

Table 10 shows averages of $P 62$ for the population of workers in HRS 2008 who were respondents in the Internet interview. ${ }^{12}$ The average increased from $58.2 \%$ to $61.7 \%$. This is a large increase over a short time period—a little more than a year for some respondents; less than six months for others. To put that change in perspective, the labor force participation rate of the older population has been increasing during the 1990s and particularly in the 2000s: In 2003 the rate among those 60-64 was 51\%, and was $54.1 \%$ in 2008. The increase over five years was 3.1 percentage points, about the same as the increase in P62 over six to 12 months. If the future actual labor force participation is well-predicted by $P 62$, these data suggest an acceleration of the trend toward higher participation.

We note, however, that the stock market reached its low in March 2009— just a month before the HRS Internet survey was initially fielded. Since then, it has recouped some of its earlier losses, so possibly some of the negative effect of the stock market on wealth has dissipated. Also, the unemployment rate today is slightly higher than during the Internet survey. But most importantly, any expectations among respondents at the time of the survey that the unemployment rate would recover quickly were not realized. Instead, the mood about the labor market is likely worse today than in May 2009.

The table shows P62 both in HRS 2008 and in 2009 according to work status in the 2009 Internet survey. There are 145 individuals who were working in 2008 and so

\footnotetext{
${ }^{12}$ In HRS 2008 P62 was only asked of workers less than age 62. In the Internet survey it was asked irrespective of labor force status so that we have responses from people who had stopped working between the two surveys as well as from those who were still working.
} 
were asked about $P 62$, but who were not working at the time of the Internet survey. When they were working in 2008, their average $P 62$ was just $44.7 \%$. That low value compared with P62 among those who were still working in 2009 shows the power of P62 to predict future labor force participation. But a striking comparison is between the change in $P 62$ across the two groups: Among those who continued to work, $P 62$ increased by 5.0 percentage points; among those who stopped working, $P 62$ declined by 4.4 percentage points. This difference in the change may well reflect the differing effects of the stock and housing market losses and of the worsening of the labor market.

Table 11 has similar statistics, but with respect to working past age 65. Qualitatively we find the same patterns as for P62: an overall increase in P65, which is driven by increases among those working in 2008 and 2009 and which offsets declines among those not working in 2009. However, the magnitude of the increases is much greater for $P 65$. The increase in $P 65$ is quite remarkable, being a little over double the increase observed in $P 62$, amounting to an increase of 7.8 percentage points (from 38.6 to 46.4). Putting it in historical perspective, the labor force participation rate among those 65-69 was 23.0\% in 1999. By 2008, it had risen to 30.7\%-a change of 7.7\%. Thus the increase in the predicted labor force participation rate in just nine months of the economic crisis was about the same magnitude as the actual increase over nine years. Even if respondents have revised their expectations about working past age 65 since May 2009 when the HRS Internet interview was fielded-possibly due to increases in the stock market and worsening of the labor market since then — it is unlikely that $P 65$ will have returned to its 2008 levels. That would suggest that the economic crisis will accelerate the trend of the past two decades of increased labor force participation among the older population.

The stratification by work status in 2009 reveals another difference with P62: The levels of $P 65$ in 2008 were much more comparable (just a 6 percentage point difference for $P 65$ compared to a 16 percentage point difference in P62). 


\section{Conclusions}

In this paper, we have studied the effects of the 2007-2009 recession on the population age 55 and older. In the course of the financial crisis that turned into the Great Recession, households suffered substantial losses in stocks and housing. Such losses particularly affect the retirement security of those in or nearing retirement. While stock values have recovered somewhat since their low point in March 2009, house prices have not. For the majority of households, housing is the most important asset. As the housing bubble grew, some households extracted home equity-also in this older population. As a result, mortgage balances increased both at the mean and the median, continuing to rise even between 2008 and 2009. The fraction of homeowners with negative home equity about quadrupled. In May 2009, individuals were pessimistic that house and stock prices would recover any time soon (i.e., over the next year). Both actual losses and pessimism led many households to reduce spending. But this trend was less pronounced among households age 65 and older-likely because this age group tends to have more home equity, and Social Security, an important part of its income, was unaffected by the economic downturn. This is in contrast to younger groups in our sample, who still rely on income from earnings. With wealth positions substantially reduced, it may be that households will pass on less wealth to the next generation. According to respondents' subjective beliefs, this will be the case and the reductions may be sizeable (about 20 percent on average). The median household will not see much change, because the effect is concentrated among households with high wealth.

The past 20 years have witnessed an increase in labor force participation among the older population. On the one hand, the economic crisis has led to increased unemployment among older workers, causing some earlier-than-anticipated retirement. But at the same time, workers expect to be working longer, compared with before the crisis. Overall, the economic downturn appears to have accelerated the trend of increases in labor force participation seen over the past 20 years. For the Social Security and Medicare programs, this accelerated trend will relieve some of the financial pressures they now face. Both programs will benefit from additional tax revenues when people work longer. Only Social Security will have to pay out higher benefits in return, but these will amount to less than the additional revenues. If anything, Medicare benefit 
payments may be lower due to some workers having employer-based health insurance, in which case Medicare is the second payer.

In sum, the economic crisis has caused households in and near retirement to suffer sizeable losses in assets. These households responded in several ways: they reduced spending and with that increased saving, they intend to work longer, and anticipate bequeathing less. 


\section{References}

Hurd, Michael D. and Susann Rohwedder, 2006, "Economic Well-Being at Older Ages: Income- and Consumption-based Poverty Measures in the HRS,” RAND Working Paper No. WR-410.

Hurd, Michael D. and Susann Rohwedder, 2009, "Wealth Change and Active Saving at Older Ages,” RAND manuscript, presented at the Annual AEA Meeting, San Francisco, January 2009.

Juster, F. Thomas, and Richard Suzman. 1995. "An Overview of the Health and Retirement Study." Journal of Human Resources, 30(5):S7-S56. 
Table 1: Household spending now compared to a year ago

\begin{tabular}{lcccc}
\hline Age & Increased & $\begin{array}{c}\text { About the } \\
\text { same }\end{array}$ & Decreased & All \\
\hline $55-64$ & 14.7 & 52.7 & 32.6 & 100.0 \\
$65-74$ & 19.2 & 56.7 & 24.1 & 100.0 \\
$75+$ & 23.9 & 59.3 & 16.8 & 100.0 \\
& & & & 100.0 \\
\hline
\end{tabular}

Table 2: Important reasons for spending decline by age band, percent stating very or somewhat important

\begin{tabular}{ccccccc}
\hline Age & $\begin{array}{c}\text { Needed to } \\
\text { reduce debt }\end{array}$ & $\begin{array}{c}\text { Lower } \\
\text { income }\end{array}$ & $\begin{array}{c}\text { Worse } \\
\text { employment }\end{array}$ & $\begin{array}{c}\text { Stocks } \\
\text { down }\end{array}$ & $\begin{array}{c}\text { Lower } \\
\text { house value }\end{array}$ & $\begin{array}{c}\text { Worried about } \\
\text { economic future }\end{array}$ \\
\hline $55-64$ & 74.5 & 76.4 & 53.7 & 56.3 & 53.4 & 86.4 \\
$65-74$ & 63.6 & 71.8 & 36.9 & 65.7 & 48.9 & 82.1 \\
$75+$ & 46.5 & 59.0 & 14.2 & 64.6 & 42.2 & 80.0 \\
Total & 69.9 & 74.1 & 47.2 & 59.2 & 51.6 & 84.9 \\
\hline
\end{tabular}

Table 3: Important reasons for spending increase by age band, percent stating very or somewhat important

\begin{tabular}{cccccc}
\hline Age & $\begin{array}{c}\text { Wealth } \\
\text { increased }\end{array}$ & $\begin{array}{c}\text { Better } \\
\text { employment }\end{array}$ & $\begin{array}{c}\text { Higher } \\
\text { mortgage pymt }\end{array}$ & $\begin{array}{c}\text { Increased } \\
\text { spdg needs }\end{array}$ & $\begin{array}{c}\text { More } \\
\text { optimistic }\end{array}$ \\
\hline $55-64$ & 42.8 & 32.2 & 31.4 & 92.3 & 42.7 \\
$65-74$ & 36.9 & 15.4 & 27.8 & 96.2 & 63.9 \\
$75+$ & 20.8 & 7.0 & 11.6 & 96.0 & 51.6 \\
& & & & & \\
Total & 37.4 & 23.0 & 27.2 & 94.2 & 51.1 \\
\hline
\end{tabular}


Table 4: Two-year change in real consumption (\%), 2001-2007 average and 2007-2009

\begin{tabular}{lcccc}
\hline & \multicolumn{2}{c}{ Percent Change in Means } & \multicolumn{2}{c}{ Percent Change in Medians } \\
& $2001-2007$ & $2007-2009$ & $2001-2007$ & 2007-2009 \\
\hline $\begin{array}{l}\text { Age 50-64 } \\
\text { Total consumption } \\
\begin{array}{l}\text { Nondurable } \\
\text { consumption }\end{array}\end{array}$ & -2.1 & -9.9 & -2.3 & -7.5 \\
\hline $\begin{array}{l}\text { Age 65+ } \\
\text { Total consumption } \\
\begin{array}{l}\text { Nondurable } \\
\text { consumption }\end{array}\end{array}$ & -1.0 & -8.6 & -0.6 & -7.3 \\
\hline
\end{tabular}

Table 5: Summary of two-year change in nondurable spending (\%)

\begin{tabular}{lcccc}
\hline & \multicolumn{2}{c}{ Means } & \multicolumn{2}{c}{ Medians } \\
\hline & $50-64$ & $65+$ & $50-64$ & $65+$ \\
$2001-2007$ & -1.0 & -4.9 & -0.6 & -3.0 \\
$2007-2009$ & -8.6 & -8.3 & -7.3 & -6.4 \\
$2007-2009$ change & & & & \\
minus average of 2- & -7.6 & -3.4 & -6.7 & -3.4 \\
year changes from & & & & \\
$2001-2007$ & & & & \\
\hline
\end{tabular}


Table 6: Home values and mortgage balances, panel [in thousand dollars]

\begin{tabular}{ccccc} 
& \multicolumn{2}{c}{$\begin{array}{c}\text { Home value } \\
\mathrm{N}=2,633\end{array}$} & \multicolumn{2}{c}{$\begin{array}{c}\text { Mortgage value } \\
\mathrm{N}=2,630\end{array}$} \\
\cline { 2 - 5 } Year & Mean & Median & Mean & Median \\
\hline 2006 & 329.4 & 230.0 & 66.5 & 14.0 \\
2008 & 304.6 & 225.0 & 66.4 & 9.0 \\
2009 & 276.8 & 200.0 & 79.0 & 30.0 \\
\hline
\end{tabular}

Only households who report owning a home in all three years are included.

Note: Imputed values allowed on amounts.

Table 7: Home values, mortgage balances and negative home equity in panel

\begin{tabular}{ccccccc} 
& \multicolumn{2}{c}{ Home value } & \multicolumn{2}{c}{ Mortgage value } & \multicolumn{2}{c}{ Negative Home equity (\%) } \\
\cline { 2 - 7 } Year & Mean & Median & Mean & Median & $\begin{array}{c}\text { All } \\
\text { homeowners }\end{array}$ & $\begin{array}{c}\text { Mortgage } \\
\text { holders only* }\end{array}$ \\
\hline 2006 & 333.7 & 250.0 & 70.2 & 17.8 & 0.8 & 1.4 \\
2008 & 315.9 & 240.0 & 69.2 & 14.0 & 0.9 & 1.8 \\
2009 & 287.5 & 220.0 & 84.0 & 35.0 & 4.0 & 6.6 \\
\hline
\end{tabular}

$\mathrm{N}=2,094$.

Notes: No imputed values included. Number of mortgage holders varies across waves:

1,000 in 2006; 950 in 2008; 1,111 in 2009.

Table 8: House price expectations, one year and five years ahead

\begin{tabular}{lcc}
\hline & 1 year from now & 5 years from now \\
\hline Any increase & 32.3 & 53.5 \\
Increase by 10\% or more & 21.3 & 47.0 \\
Increase by 20\% or more & 10.6 & 28.0 \\
Decrease by 10\% or more & 18.5 & 13.7 \\
Decrease by 20\% or more & 11.0 & 9.2 \\
$N$ & 1,820 & 1,723 \\
\hline
\end{tabular}


Table 9: Bequest probabilities and expected bequests

\begin{tabular}{|c|c|c|c|c|c|}
\hline \multirow[b]{2}{*}{ Wealth band } & \multicolumn{2}{|c|}{$\begin{array}{l}\text { Average bequest } \\
\text { probability }\end{array}$} & \multirow{2}{*}{$\begin{array}{c}\text { Average } \\
\text { wealth }\end{array}$} & \multicolumn{2}{|c|}{ Expected bequests } \\
\hline & 2008 & 2009 & & $\begin{array}{c}\text { using } 2008 \\
\text { probabilities }\end{array}$ & $\begin{array}{c}\text { using } 2009 \\
\text { probabilities }\end{array}$ \\
\hline 0 to $<\$ 10 \mathrm{k}$ & 16.2 & 23.9 & 1,808 & 292 & 432 \\
\hline$\$ 10 \mathrm{k}$ to $<\$ 100 \mathrm{k}$ & 19.8 & 20.2 & 52,125 & 10,316 & 10,549 \\
\hline$\$ 100 \mathrm{k}$ to $<\$ 500 \mathrm{k}$ & 35.2 & 33.4 & 271,660 & 95,697 & 90,843 \\
\hline$\$ 500 \mathrm{k}$ or more & 28.8 & 22.4 & $1,489,849$ & 429,211 & 334,172 \\
\hline All & 100.0 & 100.0 & 706,385 & 535,517 & 435,996 \\
\hline
\end{tabular}




\begin{tabular}{lccc}
\hline \multicolumn{4}{c}{$\begin{array}{c}\text { Table 10 } \\
\text { Average subjective probability of working past age 62 among } \\
\text { those working in }\end{array}$} \\
& & \multicolumn{2}{c}{ Won, age 51-61 } \\
\cline { 2 - 4 } & All & Working status in 2009 & Not working \\
\cline { 2 - 4 } HRS 2008 & 58.2 & 60.9 & 44.7 \\
HRS 2009 Internet & 61.7 & 65.9 & 40.3 \\
$N$ & 1062 & 917 & 145 \\
\hline
\end{tabular}

Note: Average for "all" is not equal to the weighted average of "working” and "not working” when the weights are the sample sizes. The average for "all" uses the HRS person weight adjusted for the Internet interview.

\begin{tabular}{lrrr}
\hline \multicolumn{4}{c}{$\begin{array}{c}\text { Table 11 } \\
\text { Average subjective probability of working past age 65 among } \\
\text { those working in }\end{array}$} \\
& & \multicolumn{2}{c}{ Wo08, age 51-61 } \\
\cline { 2 - 4 } & All status in 2009 & Working & Not working \\
\cline { 2 - 4 } HRS 2008 & 38.6 & 39.6 & 33.4 \\
HRS 2009 Internet & 46.4 & 49.5 & 30.8 \\
$N$ & 1056 & 911 & 145 \\
\hline
\end{tabular}

Note: Average for "all" is not equal to the weighted average of "working" and "not working" when the weights are the sample sizes. The average for "all" uses the HRS person weight adjusted for the Internet interview. 
Figure 1: Cumulative distribution of the subjective probability of a stock market gain on year ahead

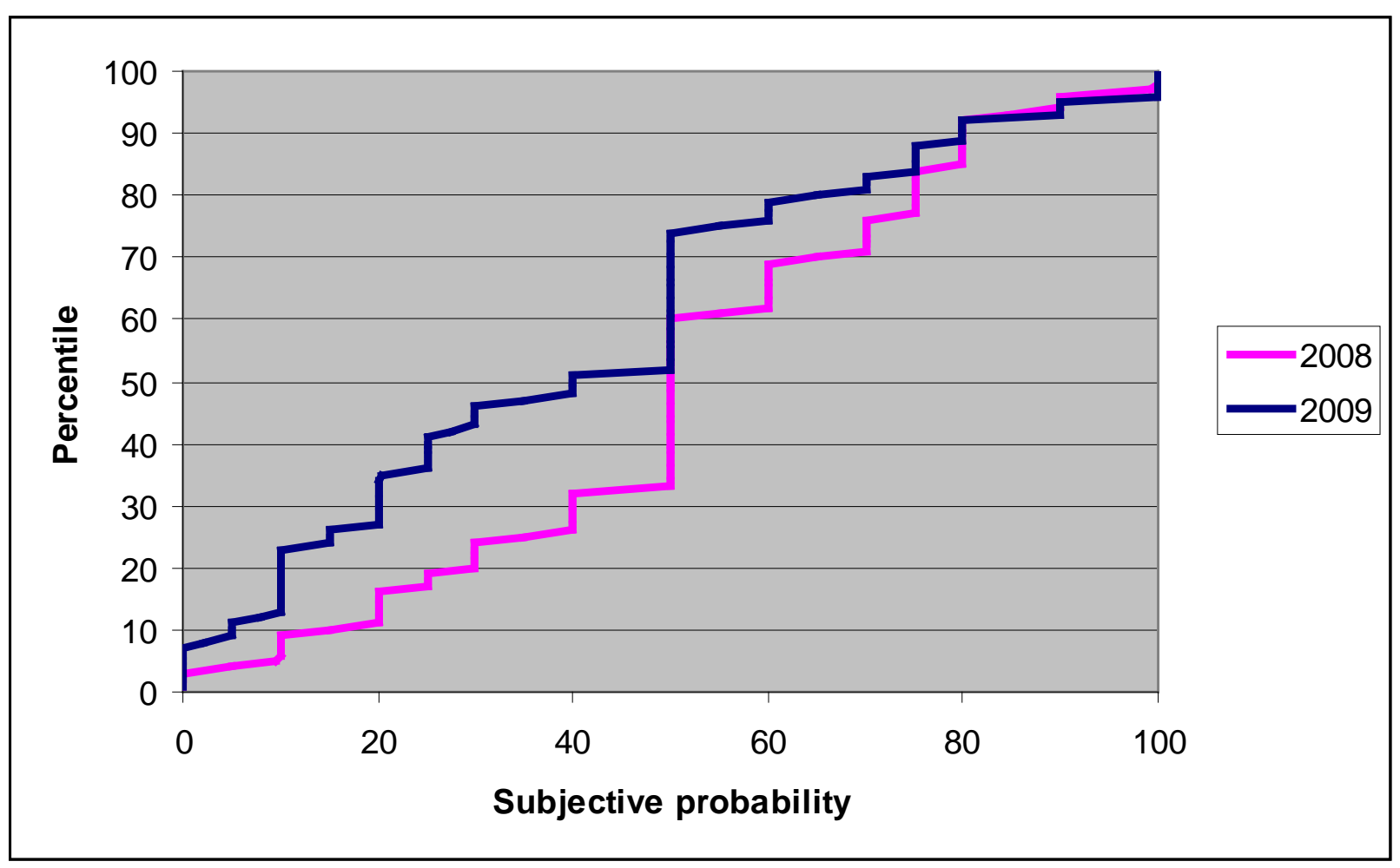

